\title{
Molecular targets of aspirin and cancer prevention
}

\author{
L Alfonso ${ }^{1}, \mathrm{G} \mathrm{Ai}^{2}$, R C Spitale ${ }^{3}$ and G J Bhat ${ }^{\star 2}$ \\ ${ }^{1}$ DYouville College School of Pharmacy, Buffalo, NY, USA; ${ }^{2}$ Department of Pharmaceutical Sciences, South Dakota State University \\ College of Pharmacy, Brookings, SD, USA and ${ }^{3}$ Department of Pharmaceutical Sciences, University of California, Irvine, CA, USA
}

Salicylates from plant sources have been used for centuries by different cultures to treat a variety of ailments such as inflammation, fever and pain. A chemical derivative of salicylic acid, aspirin, was synthesised and mass produced by the end of the 19th century and is one of the most widely used drugs in the world. Its cardioprotective properties are well established; however, recent evidence shows that it can also act as a chemopreventive agent. Its antithrombotic and anti-inflammatory actions occur through the inhibition of cyclooxygenases. The precise mechanisms leading to its anticancer effects are not clearly established, although multiple mechanisms affecting enzyme activity, transcription factors, cellular signalling and mitochondrial functions have been proposed. This review presents a brief account of the major COX-dependent and independent pathways described in connection with aspirin's anticancer effects. Aspirin's unique ability to acetylate biomolecules besides COX has not been thoroughly investigated nor have all the targets of its primary metabolite, salicylic acid been identified. Recent reports on the ability of aspirin to acetylate multiple cellular proteins warrant a comprehensive study to investigate the role of this posttranslational modification in its anticancer effects. In this review, we also raise the intriguing possibility that aspirin may interact and acetylate cellular molecules such as RNA, and metabolites such as CoA, leading to a change in their function. Research in this area will provide a greater understanding of the mechanisms of action of this drug.

The common household drug, aspirin (acetylsalicylic acid) has been around for more than a century. Its basic mechanism of action as an anti-inflammatory agent is well documented, yet newer beneficial effects and modes of action keep on adding to its ever-expanding therapeutic repertoire. It is currently used extensively as a cardioprotective and antithrombotic agent. In recent years, aspirin has generated significant interest as a potential chemopreventive agent supported by strong evidence from epidemiological data. Numerous clinical observations and laboratory studies have shown that regular use of aspirin is associated with a reduced risk for colorectal, oesophageal, breast, lung, prostate, liver and skin cancers (Harris et al, 2005; Kaiser, 2012; Sahasrabuddhe et al, 2012; Gamba et al, 2013; Veitonmaki et al, 2013). Aspirin appears to have both chemopreventive and chemotherapeutic effects (Chan et al, 2009; Holmes et al, 2010; Bastiaannet et al, 2012; Rothwell et al, 2012); however, aspirin is not currently prescribed for cancer prophylaxis owing to its adverse effects such as the risk of bleeding. Depending on the conditions being treated, aspirin is used at a range of doses from $75 \mathrm{mg}$ (antiplatelet) to $325-600 \mathrm{mg}$ (analgesic) to $1.2 \mathrm{~g}$ (anti-inflammatory) (Dovizio et al, 2013). Following oral administration, low-dose aspirin gives a peak plasma concentration of $\sim 7 \mu \mathrm{M}$; however, analgesic and anti-inflammatory doses can yield plasma concentrations ranging from 30 to $150 \mu \mathrm{M}$ (Dovizio et al, 2013). These represent plasma concentrations of intact acetylsalicylic acid. The primary metabolite of aspirin is salicylic acid. The plasma salicylate concentrations obtained from the hydrolysis of low-dose aspirin is estimated to be $15 \mu \mathrm{M}$, whereas the analgesic and anti-inflammatory doses can yield concentrations ranging from 500 to $2500 \mu \mathrm{M}$ (Dovizio et al, 2013). Incidentally, most of aspirin's anticancer effects have come to light during the course of its use as a cardiovascular prophylactic and/or analgesic agent. Studies have shown that doses ranging from 81 to $325 \mathrm{mg}$ taken over prolonged periods of time, decrease the incidence and mortality associated with colorectal cancer (Rothwell et al, 2010, 2012; Dovizio et al, 2013). Several studies using colon cancer cells and tumour models have demonstrated that aspirin can prevent cancer cell growth and induce apoptosis. Various mechanisms and cellular pathways have been identified as contributors to these effects (Thun et al, 2012; Dovizio et al, 2013).

*Correspondence: Dr GJ Bhat; E-mail: Jayarama.gunaje@sdstate.edu

Received 12 February 2014; revised 24 March 2014; accepted 8 April 2014; published online 29 May 2014

(c) 2014 Cancer Research UK. All rights reserved 0007-0920/14 


\section{PROPOSED MECHANISMS OF ACTION}

Aspirin's molecular mechanism of action was discovered in the 1970s when it was demonstrated that it irreversibly acetylates and inactivates the cyclooxygenase enzyme (prostaglandin $\mathrm{H}$-synthase) (Vane, 1971; Roth et al, 1975). The COX enzymes are involved in the synthesis of cyclic endoperoxides from arachidonic acid (AA) forming prostaglandins, prostacyclins and thromboxanes, which have a wide array of effects. Aspirin is unique because it is the only non-steroidal anti-inflammatory drug (NSAID) that irreversibly inactivates both isoforms of the COX enzymes (COX-1 and COX-2), which bring about its anti-inflammatory, antipyretic and analgesic effects. Although the precise mechanisms by which aspirin exerts its anticancer effects are yet to be elucidated, both COXdependent and independent mechanisms have been proposed (Thun et al, 2012).

\section{COX-DEPENDENT MECHANISMS}

Aspirin has been shown experimentally to induce apoptosis (Shiff et al, 1996, 2003; Gupta and DuBois, 1998; Moyad, 2001; Rao and Reddy, 2004) and to inhibit angiogenesis (Sawaoka et al, 1999; Abdelrahim and Safe, 2005) in cancer cells. Most hypotheses have focused on aspirin's ability to affect AA metabolism by permanently inactivating the 'housekeeping' COX-1 and the 'inducible' COX-2 enzymes by acetylating strategically located serine residues (Ferrandez et al, 2012).

Several COX-dependent pathways/downstream targets have been identified in aspirin's anticancer effects. Aspirin and its primary metabolite, salicylate has been shown to affect COX-2 expression at both transcriptional and posttranscriptional levels (Xu et al, 1999). One of the earlier reports demonstrated that aspirin and sodium salicylate decrease the synthesis of proinflammatory prostaglandins by reducing the transcription of COX-2 gene (Xu et al, 1999). Cyclooxygenase enzyme inhibition increases AA levels, which can prompt the conversion of sphingomyelin to ceramide, which is a well-known mediator of apoptosis (Chan et al, 1998). Aspirin is known to affect platelet function through COX inhibition. Cancer patients exhibit an increase in platelet activation that has been known to have a role in cancer progression and metastasis (Gay and Felding-Habermann, 2011). With its short plasma half-life of around $15-20 \mathrm{~min}$, aspirin is much more effective at inhibiting COX-1 in anucleate platelets as opposed to inhibiting COX-2 in monocytes, thus causing a long-lasting defect in TXA2-dependent platelet function (Ferrandez et al, 2012). COX-2 is less sensitive to aspirin because inhibition of the inducible COX-2 requires higher doses of aspirin and shorter dosing intervals as nucleated cells can promptly resynthesise the enzyme. Cyclooxygenase-2 is known to be overexpressed in colon cancer (Eberhart et al, 1994; Williams et al, 1997), and some researchers postulated that activated platelets could bring about this overexpression in colorectal cancers via the production of IL-1 $\beta$, PGDF and TGF- $\beta$ (Sciulli et al, 2005).

Whereas COX-1 acetylation by aspirin abolishes its enzymatic activity, COX-2 acetylation modifies the enzyme in such a way that it performs an incomplete reaction ultimately resulting in the generation of lipoxins (Claria and Serhan, 1995), which inhibit cancer cell proliferation and angiogenesis (Ferrandez et al, 2012). COX-2 expressing colorectal cancer tissues produces copious amounts of prostaglandin E2 (PGE2). As PGE2 causes resistance to apoptosis, stimulation of cell migration and angiogenesis, it has been implicated in the development and progression of various malignancies including those of the lung, breast and neck (Dixon et al, 2013). Human studies demonstrated that adenoma regression was more effective when PGE2 tissue levels were significantly inhibited by NSAIDs (Giardiello et al, 2004). Another study by Liao et al, 2012 discovered that COX-2 inhibition by aspirin downregulated phosphatidylinositol 3-kinase signalling, suggesting that regular aspirin use after colorectal cancer diagnosis led to increased survival among patients with mutated-PIK3CA tumours. Thus aspirin's ability to reduce colorectal cancer occurs at least in part, via the inhibition of COX-2 activity.

\section{COX-INDEPENDENT MECHANISMS}

In the face of mounting evidences, the contribution of COXindependent pathways to the anticancer effects of aspirin or its metabolite, salicylate cannot be discounted. Aspirin and salicylates have been found to inhibit I $\kappa \mathrm{B}$ kinase (IKK) $\beta$ and prevent NF- $\kappa \mathrm{B}$ activation both in vivo and in vitro (Kopp and Ghosh, 1994; Yin et al, 1998; McCarty and Block, 2006). Till date, the only COXindependent target that is known to directly interact with aspirin or salicylic acid is IKK. Transcription of several proteins involved in inflammatory responses and angiogenesis is promoted by NF- $\kappa$ B (McCarty and Block, 2006); therefore, inhibition of this pathway may also contribute to the observed anticancer effects. However, some studies showed that aspirin-mediated induction of apoptosis in human colorectal cancer models requires activation of the NF- $\kappa \mathrm{B}$ signalling pathway (Stark et al, 2007). It is possible that this differential effect may be related to the specific cell types and tissue environments. Aspirin has also been known to interfere with extracellular-signal-regulated kinase (ERK) signalling leading to its inhibition by preventing the binding of c-Raf with Ras in vitro (Pan et al, 2008). This observation is important because the ERK pathway is involved in cellular processes like proliferation, differentiation and survival. In view of the high levels of Ras mutations observed in many cancers leading to the activation of the ERK pathway (Bos, 1989), the finding that aspirin interferes with ERK signalling is very significant.

Aspirin can also affect mitochondrial functions. It increases the mitochondrial membrane permeability, causing the release of cytochrome c, resulting in the activation of caspases followed by cell apoptosis in several cell lines (Bellosillo et al, 1998; Zimmermann et al, 2000; Dikshit et al, 2006). Another mechanism includes the inhibition of mitochondrial calcium uptake by salicylic acid (Nunez et al, 2006) leading to anti-proliferative effects.

One of the major oncogenic pathways in colon cancer is the $\mathrm{Wnt} / \beta$-catenin pathway. Aspirin is known to cause a concentration-dependent inhibition of this pathway in vitro (Bos et al, 2006). A recent study in colon cancer cells by Pathi et al, 2012 demonstrated that aspirin caused caspase-dependent proteolysis of Sp1, Sp3 and Sp4 (specificity protein) transcription factors, which was associated with downregulation of several Sp-regulated genes involved in cell survival, proliferation and angiogenesis. In another study, it was demonstrated that inhibition of 6-phosphofructo-1-kinase activity by aspirin and salicylic acid caused a decrease in glucose consumption and inhibition of cell proliferation (Spitz et al, 2009). Law et al showed that salicylateinduced cell growth arrest is associated with inhibition of p70s6k and downregulation of c-Myc, Cyclin D1, Cyclin A and proliferating cell nuclear antigen (Law et al, 2000). These reports indicate that the targets of aspirin and salicylates may directly or indirectly modulate the activity of transcription factors, cell signalling proteins, metabolic enzymes and mitochondrial proteins.

\section{EXTRA-COX ACETYLATION TARGETS}

Aspirin is mainly absorbed intact in the gastrointestinal (GI) tract (Leonards, 1962; Bridges et al, 1975) and later hydrolysed to the 
acetate and salicylate ions as it circulates in the plasma (Leonards, 1962). Hydrolysis can also occur during passage through the liver and other organs. It is well known that the acetyl group of aspirin can acetylate several proteins other than COX (Alfonso et al, 2009b; Marimuthu et al, 2011; Bateman et al, 2013). Experiments with radiolabelled ${ }^{3} \mathrm{H}$ or ${ }^{14} \mathrm{C}$ aspirin demonstrated that aspirin acetylates several proteins in vitro and in vivo through a transacetylation reaction (Hawkins et al, 1968; Caterson et al, 1978; Rainsford et al, 1983). Aspirin acetylates human serum albumin and fibrinogen in vitro and in vivo (Hawkins et al, 1968; Bjornsson et al, 1989). It can also acetylate several other proteins and biomolecules, such as haemoglobin, DNA, RNA, histones, transglutaminase as well as other plasma constituents including hormones and enzymes (Pinckard et al, 1968; Lai et al, 2010). In a remarkable study, it was found that in vivo administration of radiolabelled ${ }^{3} \mathrm{H}$ or ${ }^{14} \mathrm{C}$ aspirin to rats, led to the binding of the acetyl group of aspirin to several proteins, glycoproteins and lipids of the stomach, kidney, liver and bone marrow (Rainsford et al, 1983), demonstrating that the acetyl group is able to reach distant organs.

In a previous study, we demonstrated (Alfonso et al, 2009a) that aspirin acetylates the tumour suppressor protein, p53 at lysine 382 in MDA-MB-231 breast cancer cells. This acetylation was observed at the physiologically achievable concentration of $100 \mu \mathrm{M}$. MDAMB-231 cells contain a mutant form of p53 (codon 280, Arg to Lys). This effect correlated with increased p53 DNA-binding activity and the expression of two of its target genes, p21CIP1 and Bax. Aspirin also acetylated p53 in other cell lines carrying different p53 mutations (unpublished data); however, it is not clear at this stage, if this changes the functional activity of $\mathrm{p} 53$. In view of the reports that, p53 is mutated and inactivated in $\sim 50 \%$ of all tumours, our observation that aspirin can acetylate mutant $\mathrm{p} 53$, is an important finding. Although further research is required, it is possible that acetylation of mutant $\mathrm{p} 53$ by aspirin, in some cases, may restore its DNA-binding properties leading to target gene expression. If this is the case, aspirin may curtail cancer cell growth through reactivation of mutant $\mathrm{p} 53$. In another study, using antibodies specific for the recognition of acetylated lysine residues, we found that aspirin acetylates multiple proteins in a dosedependent manner in rat liver epithelial cells and HCT-116 colon cancer cells (Alfonso et al, 2009b; Marimuthu et al, 2011). In HCT116 cells (Marimuthu et al, 2011), aspirin acetylated at least 33 different proteins, which included histones, cytoskeletal and heat shock proteins, glycolytic and pentose phosphate pathway enzymes and ribosomal and mitochondrial proteins. A detailed investigation on how the acetylation effects the functional activity of these proteins is yet to be conducted. It is to be noted that our study only identified proteins that are acetylated at lysine residues, as made possible by the use of the anti-acetyl lysine antibody and mass spectrometry. Aspirin can also acetylate proteins at serine and cysteine residues (Qin et al, 1993; Alfonso et al, 2009b; Bateman et al, 2013), but these acetylation events were not detected by our approach. In a recent report Bateman et al (2013) reported the ability of aspirin to acetylate 120 proteins in HCT15 human adenocarcinoma cells using an alkyne-aspirin chemical reporter. The identified enzymes included several metabolic pathway enzymes, structural proteins, proteins involved in translation, proteasomal subunits, mitochondrial proteins and histones. Among these, histones appear to be most intriguing owing to their prominent role in transcriptional regulation. Histone acetylation can cause charge neutralisation of basic lysine residues leading to changes in the chromatin structure and transcription of genes. It is possible that chemical acetylation by aspirin may have a role in shifting the equilibrium of the enzymatic acetylation/ deacetylation process that occurs naturally in cells bringing about major changes in gene expression.

Studies show that aspirin is more effective in decreasing the incidence of colon cancer compared with the distal tissues (e.g., breast, lung, prostate, liver and skin). One possibility is that intestinal epithelial cells may be exposed to higher concentration of intact aspirin immediately following oral administration compared with the measured plasma levels, which reflects concentration after first-pass metabolism. A direct exposure of GI epithelial cells to higher concentration of intact aspirin may lead to greater degree of acetylation of proteins in the GI cells than the distal tissues. Plasma concentration of the intact aspirin at various doses following oral administration has been published; however, a similar estimation in the GI tract has not been reported. Future work is required to determine whether the significantly greater cancer risk reduction observed in GI tract is related to increased acetylation of proteins as compared with the distal tissues.

\section{CHEMICAL INTERACTIONS OF ASPIRIN WITHIN THE CELL}

Many natural products found in plants and bacterial cells have intrinsic reactivity properties as electrophiles (Drahl et al, 2005).
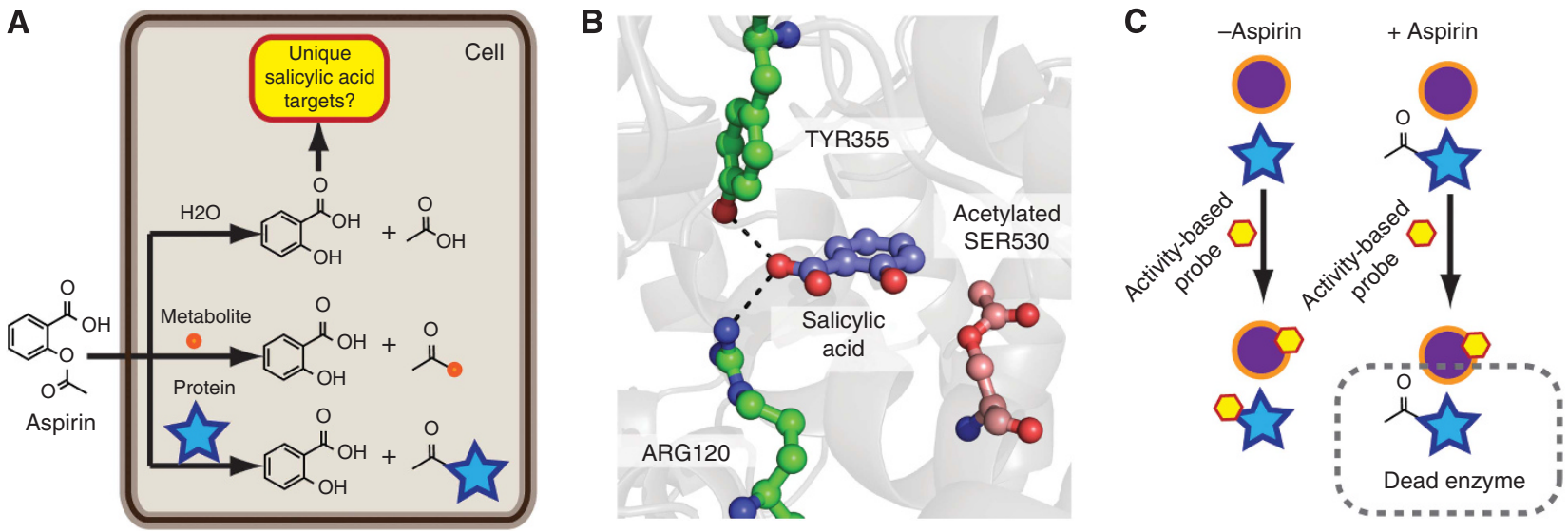

Figure 1. Aspirin chemical reactivity. (A) Aspirin can easily enter cells and react with many different cellular chemicals. For example, aspirin can react with water to form the hydrolysis byproduct salicylic acid. Aspirin can also react with nucleophilic metabolites (e.g., glutathione) or proteins to produce acetylated products. (B) Aspirin can bind to enzyme active sites and modify nucleophilic functional groups. For example in COX-1 aspirin acetylates SER530, rendering the enzyme inactive. (C) Schematic of activity-based profiling to understand sites of acetylation on aspirin. In this experiment, aspirin acetylates active site nucleophilic amino acids. Then the pool of proteins is incubated with activity-based probes to reveal catalytically inactive functional groups, within the now-dead enzymes. 
Reaction with reactive small molecules, including cellular metabolites, damaged metabolic intermediates or exogenous agents can result in drastic rewiring of essential cellular processes, ultimately resulting in changes in cellular phenotype (Moellering and Cravatt, 2013; Wang et al, 2014). Although such interactions have been observed for quite some time, their effect on cancer cell biology is only recently being investigated in quite detail. The reactive nature of aspirins acetyl group ( $t_{1 / 2}$ in solution is $30 \mathrm{~min}$ ) suggests that aspirin may also have off-target chemical reactions that can contribute to its biological effect.

Once aspirin enters the cell, a good portion of the compound is going to be quenched owing to hydrolysis reaction with aqueous solvent (Figure 1A). This reaction and others present an opportunity for high concentrations of salicylic acid in the cell, which may also interact with cellular molecules and disrupt their activity. Such an interaction has been described with NF- $\kappa \mathrm{B}$, an important transcription factor (Kopp and Ghosh, 1994).

In addition to hydrolytic reactions, many reactive metabolites could, in principle, also react with aspirin. For example, thiolcontaining glutathione can have an intracellular concentration in the millimolar range (Figure 1A) (Bennett et al, 2009). Glutathione's near-neutral $\mathrm{pKa}$ and high reactivity would catalyse acetylation and quench its reactivity, thus taking away its ability to prevent oxidative stress (Arnold et al, 1995). Such interactions could remodel the cells metabolic profile and also have dramatic effects on stress-response pathways involving metabolite quenchers. At present, there is a lack of investigation into the alterations that aspirin has on the metabolic pool of the cell.

Recent evidence has shown that the introduction of electrophiles into the cell can alter enzyme activity by quenching lysine and cysteine reactivity (Wang et al, 2014). In these cases, the reactions of these molecules are enhanced by binding into active sites to lower the transition state and then reacting to quench activity. This is similar to aspirin's role to render the COX enzymes catalytically dead (Figure 1A and B). However, additional examples, beyond the COX enzymes are severely limited. An exciting experimental platform to explore this possibility is activity-based profiling. In this way proteomes or cells would be exposed to concentrations of aspirin, allowing the chemical to react with protein side chains, covalently. Then, activity-based probes can be used to explore the changes in reactivity of active site-localised nucleophiles (Figure 1C). In this way, protein-reactive groups could be identified and enzymes whose activity is altered because of aspirin could be identified. Further, in many cases the targets of activitybased probes are already known (Simon et al, 2013), so this would also yield protein identification in one experiment. Some work has already demonstrated that there is widespread acetylation of biomolecules owing to aspirin's reactivity (Marimuthu et al, 2011; Bateman et al, 2013). Therefore, there is a serious need to utilise optimised chemical and proteomic methods to interrogate the reactivity of both aspirin and salicylic acid.

\section{UNDERSTUDIED POTENTIAL TARGETS OF ASPIRIN}

A significant amount of research has been focused on the interactions of aspirin with proteins. Overall, these studies have revealed that aspirin's reactivity can be increased by structural interactions that increase binding affinity for either steric blocking of enzymatic transformations, or the covalent acetylation of nucleophilic functional groups to render proteins enzymatically dead (Figure 2A). Nevertheless, the cell is composed of many different biologics, some of which are also inherently reactive and thus, may also sense aspirin and become modified.

Two understudied potential aspirin-interacting cellular molecules are RNA and metabolites. First, a significant portion of
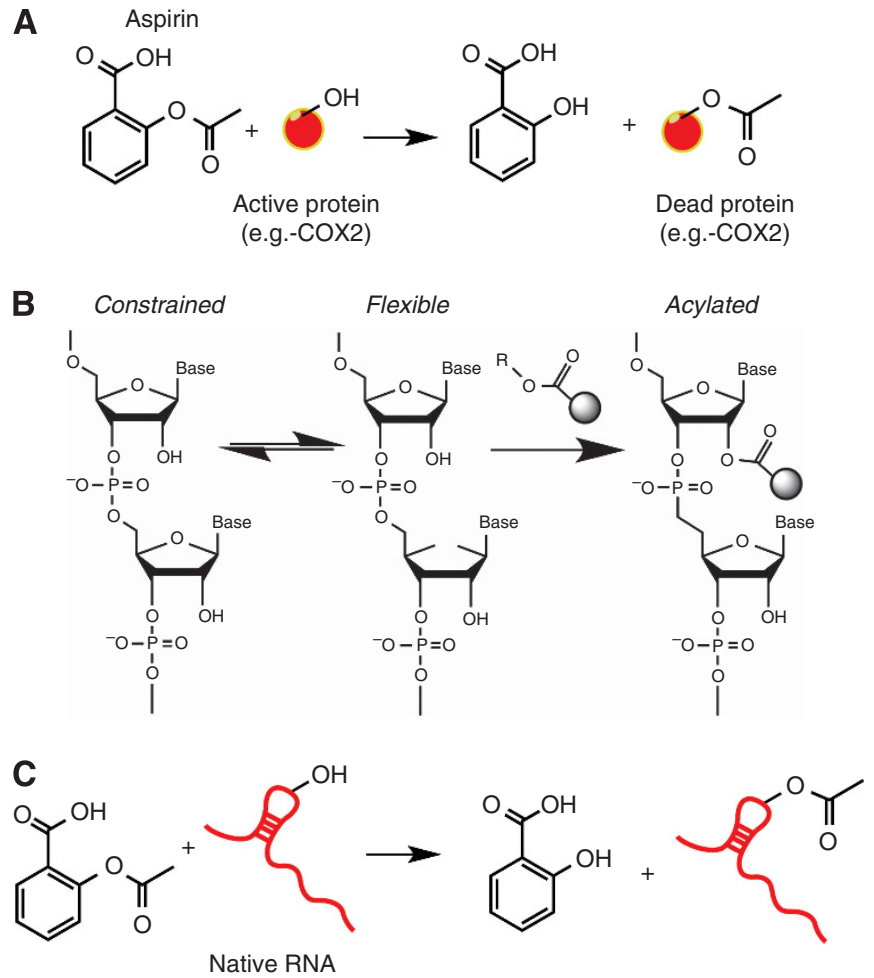

Figure 2. Aspirin reactivity with RNA. (A) Aspirin reacts with serine hydroxyl groups in the active site of enzymes. This acetylation renders the enzyme inactive. (B) RNA acetylation can be performed by introducing electrophiles into cells. In this case reactivity of $2^{\prime}-\mathrm{OH}$ groups is facilitated by RNA structure and the proximity of the $2^{\prime}-\mathrm{OH}$ to the phosphate backbone. (C) Chemical reaction between aspirin and RNA, acetylating RNA $2^{\prime}-\mathrm{OH}$ groups.

cellular mass is made up of RNA molecules. And, it has been shown that RNAs can become modified by exogenous chemicals introduced into the cellular milieu. Some of these compounds rely on RNA's inherent reactivity as a nucleophile. RNA structure probes are a class of molecules that take advantage of RNA reactivity. For example, SHAPE (selective $2^{\prime}$ hydroxyl acylation and primer extension). In SHAPE, the reactivity of the $2^{\prime}$-hydroxyl in RNA is gated by local nucleotide flexibility (Merino et al, 2005). In other words, the $2^{\prime}$-hydroxyl is reactive at single-stranded and conformationally flexible positions but is unreactive at nucleotides constrained by base pairing. In solution, $2^{\prime}-\mathrm{OH}$ functional groups have $\mathrm{pKa}$ values that range from 12 to 14 (Velikyan et al, 2001). Nevertheless, it has been shown that RNA functional groups can alter their $\mathrm{pKa}$ values to approach biological conditions, and these changes are dependent on RNA structure (Ryder et al, 2001; Guo et al, 2009). SHAPE utilises electrophilic compounds that have carbonyl-carbon reactive centres, mostly anhydrides (Figure 2B). Such electrophilic centres are similar to those found in aspirin. Further, it has also been shown that certain $2^{\prime}-\mathrm{OH}$ groups can be hyper-reactive, owing to their intermolecular interactions with RNA functional groups nearby in space that transiently deprotonate the $2^{\prime}-\mathrm{OH}$ for activation (McGinnis et al, 2012). Overall, these studies hint that $2^{\prime}-\mathrm{OH}$ reactivity could be modulated to interact and catalyse an acetylation reaction with aspirin.

The biological consequences of RNA acetylation could be quite large (Figure 2C). For example, the $2^{\prime}-\mathrm{OH}$ is an important functional group in splicing (Fica et al, 2013). The binding of aspirin to the RNA and acetylation of an activated $2^{\prime}-\mathrm{OH}$ could in theory change the splicing pattern of a gene, therefore producing an alternative RNA isoform and protein product. Additionally 2 '-OH groups have important roles in RNA structure and function 
A

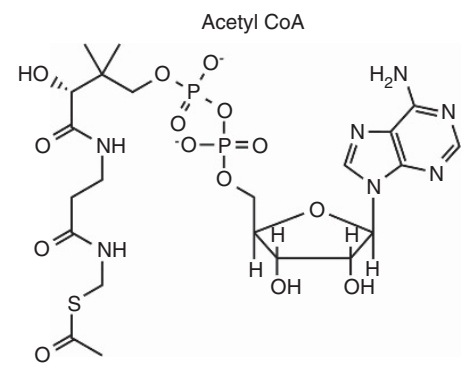

B

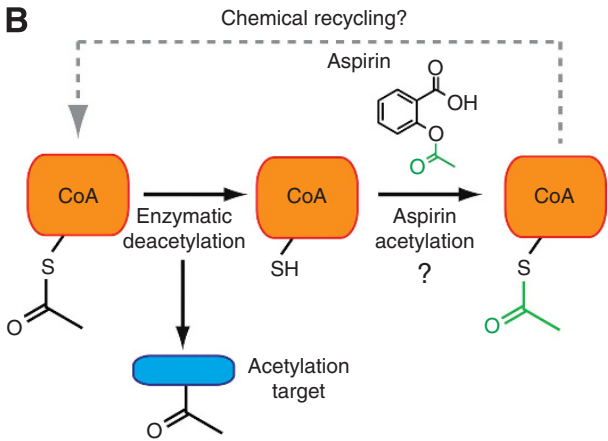

Figure 3. Potential of aspirin to acetylate Acetyl-CoA. (A) Chemical structure of acetyl-CoA. (B) Schematic demonstrating the possibility that aspirin acetylation keeps a high steady state level of acetyl-CoA in the cell, through a chemical recycling mechanism.

(Moss, 2013). The acetylation of $2^{\prime}-\mathrm{OH}$ groups may alter the ability of a RNA to fold properly and ultimately result in an incorrect conformation and therefore disruption of biology. Lastly, it has been shown that RNA $2^{\prime}$-hydroxyl functional groups can have a role in the recognition of protein partners (Lunde et al, 2007). The capping of these interactions by aspirin could in principle alter the binding affinity or change the ability of the RNA to be sensed by an RNA-binding protein. These are just a few of the many potential biological consequences that RNA acetylation by aspirin could have on RNA biology and ultimately the many networks of a cell.

Small molecule metabolites have also been an understudied target of aspirin. Nevertheless, metabolites can be in some cases at millimolar concentration within certain cells (Bennett et al, 2009). Many such metabolites become altered by interactions with carcinogens and other exogenous agents. Therefore it seems plausible that the reaction of certain metabolites with aspirin could alter the metabolic landscape and have substantial effects on the biology of cells. Which metabolites would be so important and potentially reactive? One such molecule is Acetyl coenzyme A or acetyl-CoA. Acetyl-CoA is an important molecule in metabolism and is used for acetyl transfer reactions to many biological molecules. Its main function is to convey the carbon atoms within the acetyl moiety to the citric acid cycle (Krebs cycle). In chemical structure, acetyl-CoA is the thioester between the acyl carrier domain of the molecule and the coenzyme A (Figure 3A).

One of the most important functions of the acetyl-CoA donor is the regulation of chromatin state and therefore, transcription (Marmorstein and Roth, 2001; Marmorstein, 2001). One such potential way the acetylation of CoA could alter gene expression would be through chemical recycling of the acetyl-CoA in the cell (Figure 3B). This would thus increase or maintain a high steady state level of acetyl-CoA to serve as a substrate for acetyl transferase enzymes. Indeed, changes to acetylation status of many proteins have been tagged as an important process in neoplasm, depending on the target gene loci involved (Archer and Hodin, 1999; Wang et al, 2001; Kouraklis and Theocharis, 2003). Overall, the mere suggestion of acetyl-CoA activation by aspirin being an important alteration to the metabolic state of the cell is a rather intriguing possibility. Future efforts need to be extended to uncover novel targets of aspirin and aspirin-induced acetylation inside the cell.

\section{CONCLUSION}

Scientific evidence suggests that both constituent groups of aspirin that is, the acetyl and salicylate moieties have distinct targets that may together contribute to its anticancer effects. Although the acetyl group of aspirin did get its fair share of attention after the discovery of its mechanism of action through the inhibition of the COX enzymes in the 1970s, it has since been largely ignored. Acetylation is a unique characteristic of aspirin that is not shared with any other NSAID. Acetylation is also a critical endogenous posttranslational modification that affects the function of a wide array of proteins in the body (Choudhary et al, 2009). The ubiquitous nature of acetylation was demonstrated by Zhao et al, 2010 , who showed that $>1000$ proteins are naturally acetylated in human liver cells. These included 44 metabolic pathway enzymes involved in glycolysis, fatty acid and glycogen metabolism, tricarboxylic acid and urea cycles. Acetylation has been associated with the control of enzyme activity by activating, inactivating or destabilising metabolic enzymes (Xu et al, 2013) and may allow cells to respond to changes in metabolic demands (Wang et al, 2010). Deregulated acetylation has been implicated in diseased states such as cancer (Xu et al, 2013) and therefore, identification of acetylatable targets of aspirin and modification in their function may shed light on the chemopreventive action of this drug. Aspirin's ability to chemically acetylate endogenous proteins/ biomolecules has immense therapeutic significance. Further research will provide a greater understanding of how the vast array of recently identified proteins/biomolecules acetylated by aspirin contributes to its chemopreventive properties.

\section{ACKNOWLEDGEMENTS}

Support from the Translational Cancer Research Seed Grant, funded as 2010 Research Initiative Center by the State of South Dakota, and from NIH (5RO3CA133061-02) to GJB is gratefully acknowledged.

\section{REFERENCES}

Abdelrahim M, Safe S (2005) Cyclooxygenase-2 inhibitors decrease vascular endothelial growth factor expression in colon cancer cells by enhanced degradation of Sp1 and Sp4 proteins. Mol Pharmacol 68(2): 317-329.

Alfonso LF, Srivenugopal KS, Arumugam TV, Abbruscato TJ, Weidanz JA, Bhat GJ (2009a) Aspirin inhibits camptothecin-induced p21CIP1 levels and potentiates apoptosis in human breast cancer cells. Int J Oncol 34(3): 597-608.

Alfonso LF, Srivenugopal KS, Bhat GJ (2009b) Does aspirin acetylate multiple cellular proteins?(Review). Mol Med Rep 2(4): 533-537.

Archer SY, Hodin RA (1999) Histone acetylation and cancer. Curr Opin Genet $\operatorname{Dev}$ 9(2): 171-174.

Arnold JT, Wilkinson BP, Sharma S, Steele VE (1995) Evaluation of chemopreventive agents in different mechanistic classes using a rat tracheal epithelial cell culture transformation assay. Cancer Res 55(3): 537-543. 
Bastiaannet E, Sampieri K, Dekkers OM, de Craen AJ, van Herk-Sukel MP, Lemmens V, van den Broek CB, Coebergh JW, Herings RM, van de Velde CJ, Fodde R, Liefers GJ (2012) Use of aspirin postdiagnosis improves survival for colon cancer patients. Br J Cancer 106(9): 1564-1570.

Bateman LA, Zaro BW, Miller SM, Pratt MR (2013) An alkyne-aspirin chemical reporter for the detection of aspirin-dependent protein modification in living cells. J Am Chem Soc 135(39): 14568-14573.

Bellosillo B, Piqué M, Barragán M, Castaño E, Villamor N, Colomer D, Montserrat E, Pons G, Gil J (1998) Aspirin and salicylate induce apoptosis and activation of caspases in B-cell chronic lymphocytic leukemia cells. Blood 92(4): 1406-1414.

Bennett BD, Kimball EH, Gao M, Osterhout R, Van Dien SJ, Rabinowitz JD (2009) Absolute metabolite concentrations and implied enzyme active site occupancy in Escherichia coli. Nat Chem Biol 5(8): 593-599.

Bjornsson T, Schneider D, Berger H (1989) Aspirin acetylates fibrinogen and enhances fibrinolysis. Fibrinolytic effect is independent of changes in plasminogen activator levels. J Pharmacol Exp Ther 250(1): 154-161.

Bos CL, Kodach LL, van den Brink GR, Diks SH, van Santen MM, Richel DJ, Peppelenbosch MP, Hardwick JC (2006) Effect of aspirin on the $\mathrm{Wnt} / \beta$-catenin pathway is mediated via protein phosphatase $2 \mathrm{~A}$. Oncogene 25(49): 6447-6456.

Bos JL (1989) Ras oncogenes in human cancer: a review. Cancer Res 49(17): 4682-4689.

Bridges KR, Schmidt GJ, Jensen M, Cerami A, Bunn HF (1975) The acetylation of hemoglobin by aspirin. In vitro and in vivo. J Clin Invest 56(1): 201-207.

Caterson RJ, Duggin GG, Horvath J, Mohandas J, Tiller D (1978) Aspirin, protein transacetylation and inhibition of prostaglandin synthetase in the kidney. Br J Pharmacol 64(3): 353-358.

Chan AT, Ogino S, Fuchs CS (2009) Aspirin use and survival after diagnosis of colorectal cancer. JAMA 302(6): 649-658.

Chan TA, Morin PJ, Vogelstein B, Kinzler KW (1998) Mechanisms underlying nonsteroidal antiinflammatory drug-mediated apoptosis. Proc Natl Acad Sci 95(2): 681-686.

Choudhary C, Kumar C, Gnad F, Nielsen ML, Rehman M, Walther TC, Olsen JV, Mann M (2009) Lysine acetylation targets protein complexes and co-regulates major cellular functions. Science 325(5942): 834-840.

Claria J, Serhan CN (1995) Aspirin triggers previously undescribed bioactive eicosanoids by human endothelial cell-leukocyte interactions. Proc Natl Acad Sci 92(21): 9475-9479.

Dikshit P, Chatterjee M, Goswami A, Mishra A, Jana NR (2006) Aspirin induces apoptosis through the inhibition of proteasome function. J Biol Chem 281(39): 29228-29235.

Dixon DA, Blanco FF, Bruno A, Patrignani P (2013) Mechanistic aspects of COX-2 expression in colorectal neoplasia. Recent Results Cancer Res 191: $7-37$.

Dovizio M, Bruno A, Tacconelli S, Patrignani P (2013) Mode of action of aspirin as a chemopreventive agent. Recent Results Cancer Res 191: 39-65.

Drahl C, Cravatt BF, Sorensen EJ (2005) Protein-reactive natural products. Angew Chem Int Ed Engl 44(36): 5788-5809.

Eberhart CE, Coffey RJ, Radhika A, Giardiello FM, Ferrenbach S, DuBois RN (1994) Up-regulation of cyclooxygenase 2 gene expression in human colorectal adenomas and adenocarcinomas. Gastroenterology 107(4): 1183-1188.

Ferrandez A, Piazuelo E, Castells A (2012) Aspirin and the prevention of colorectal cancer. Best Pract Res Clin Gastroenterol 26(2): 185-195.

Fica SM, Tuttle N, Novak T, Li NS, Lu J, Koodathingal P, Dai Q, Staley JP, Piccirilli JA (2013) RNA catalyses nuclear pre-mRNA splicing. Nature 503(7475): 229-234.

Gamba CA, Swetter SM, Stefanick ML, Kubo J, Desai M, Spaunhurst KM, Sinha AA, Asgari MM, Sturgeon S, Tang JY (2013) Aspirin is associated with lower melanoma risk among postmenopausal Caucasian women: the Women's Health Initiative. Cancer 119(8): 1562-1569.

Gay LJ, Felding-Habermann B (2011) Contribution of platelets to tumour metastasis. Nat Rev Cancer 11(2): 123-134.

Giardiello FM, Casero Jr RA, Hamilton SR, Hylind LM, Trimbath JD, Geiman DE, Judge KR, Hubbard W, Offerhaus GJA, Yang VW (2004) Prostanoids, ornithine decarboxylase, and polyamines in primary chemoprevention of familial adenomatous polyposis. Gastroenterology 126(2): 425-431.

Guo M, Spitale RC, Volpini R, Krucinska J, Cristalli G, Carey PR, Wedekind JE (2009) Direct Raman measurement of an elevated base $\mathrm{pKa}$ in the active site of a small ribozyme in a precatalytic conformation. J Am Chem Soc 131(36): 12908-12909.
Gupta RA, DuBois RN (1998) Aspirin, NSAIDS, and colon cancer prevention: mechanisms? Gastroenterology 114(5): 1095-1098.

Harris RE, Beebe-Donk J, Doss H, Doss DB (2005) Aspirin, ibuprofen, and other non-steroidal anti-inflammatory drugs in cancer prevention: a critical review of non-selective COX-2 blockade (review). Oncol Rep 13(4): 559-583.

Hawkins D, Pinckard RN, Farr RS (1968) Acetylation of human serum albumin by acetylsalicylic acid. Science 160(3829): 780-781.

Holmes MD, Chen WY, Li L, Hertzmark E, Spiegelman D, Hankinson SE (2010) Aspirin intake and survival after breast cancer. J Clin Oncol 28(9): $1467-1472$.

Kaiser J (2012) Will an aspirin a day keep cancer away? Science 337(6101): 1471-1473.

Kopp E, Ghosh S (1994) Inhibition of NF-kappa B by sodium salicylate and aspirin. Science 265(5174): 956-959.

Kouraklis G, Theocharis S (2003) Histone acetylation and cancer. Acta Oncol 42(7): 792.

Lai TS, Davies C, Greenberg CS (2010) Human tissue transglutaminase is inhibited by pharmacologic and chemical acetylation. Protein Sci 19(2): 229-235.

Law BK, Waltner-Law ME, Entingh AJ, Chytil A, Aakre ME, Norgaard P, Moses HL (2000) Salicylate-induced growth arrest is associated with inhibition of p70s6k and down-regulation of c-myc, cyclin D1, cyclin A, and proliferating cell nuclear antigen. J Biol Chem 275(49): 38261-38267.

Leonards JR (1962) Presence of acetylsalicylic acid in plasma following oral ingestion of aspirin. Proc Soc Exp Biol Med 110(2): 304-308.

Liao X, Lochhead P, Nishihara R, Morikawa T, Kuchiba A, Yamauchi M, Imamura Y, Qian ZR, Baba Y, Shima K, Sun R, Nosho K, Meyerhardt JA, Giovannucci E, Fuchs CS, Chan AT, Ogino S (2012) Aspirin use, tumor PIK3CA mutation, and colorectal-cancer survival. N Engl J Med 367(17): 1596-1606.

Lunde BM, Moore C, Varani G (2007) RNA-binding proteins: modular design for efficient function. Nat Rev Mol Cell Biol 8(6): 479-490.

Marimuthu S, Chivukula RS, Alfonso LF, Moridani M, Hagen FK, Bhat GJ (2011) Aspirin acetylates multiple cellular proteins in HCT-116 colon cancer cells: Identification of novel targets. Int J Oncol 39(5): 1273-1283.

Marmorstein R (2001) Structure and function of histone acetyltransferases. Cell Mol Life Sci 58(5-6): 693-703.

Marmorstein R, Roth SY (2001) Histone acetyltransferases: function, structure, and catalysis. Curr Opin Genet Dev 11(2): 155-161.

McCarty MF, Block KI (2006) Preadministration of high-dose salicylates, suppressors of NF- $\mathrm{\kappa B}$ activation, may increase the chemosensitivity of many cancers: an example of proapoptotic signal modulation therapy. Integr Cancer Ther 5(3): 252-268.

McGinnis JL, Dunkle JA, Cate JH, Weeks KM (2012) The mechanisms of RNA SHAPE chemistry. J Am Chem Soc 134(15): 6617-6624.

Merino EJ, Wilkinson KA, Coughlan JL, Weeks KM (2005) RNA structure analysis at single nucleotide resolution by selective 2'-hydroxyl acylation and primer extension (SHAPE). J Am Chem Soc 127(12): 4223-4231.

Moellering RE, Cravatt BF (2013) Functional lysine modification by an intrinsically reactive primary glycolytic metabolite. Science 341(6145): 549-553.

Moss WN (2013) Computational prediction of RNA secondary structure. Methods Enzymol 530: 3-65.

Moyad MA (2001) An introduction to aspirin, NSAids, and COX-2 inhibitors for the primary prevention of cardiovascular events and cancer and their potential preventive role in bladder carcinogenesis: part II. Semin Urol Oncol 19(4): 306-316.

Nunez L, Valero RA, Senovilla L, Sanz-Blasco S, Garcia-Sancho J, Villalobos C (2006) Cell proliferation depends on mitochondrial Ca2 + uptake: inhibition by salicylate. J Physiol 571(Pt 1): 57-73.

Pan MR, Chang HC, Hung WC (2008) Non-steroidal anti-inflammatory drugs suppress the ERK signaling pathway via block of Ras/c-Raf interaction and activation of MAP kinase phosphatases. Cell Signal 20(6): 1134-1141.

Pathi S, Jutooru I, Chadalapaka G, Nair V, Lee SO, Safe S (2012) Aspirin inhibits colon cancer cell and tumor growth and downregulates specificity protein (Sp) transcription factors. PloS one 7(10): e48208.

Pinckard RN, Hawkins D, Farr RS (1968) In vitro acetylation of plasma proteins, enzymes and DNA by aspirin. Nature 219(5149): 68-69.

Qin W, Smith JB, Smith DL (1993) Reaction of aspirin with cysteinyl residues of lens gamma-crystallins: a mechanism for the proposed anti-cataract effect of aspirin. Biochim Biophys Acta 1181(2): 103-110. 
Rainsford K, Schweitzer A, Brdne K (1983) Distribution of the acetyl compared with the salicyl moiety of acetylsalicylic acid: Acetylation of macromolecules in organs wherein side-effects are manifest. Biochem Pharmacol 32(7): 1301-1308.

Rao CV, Reddy BS (2004) NSAIDs and chemoprevention. Curr Cancer Drug Targets 4(1): 29-42.

Roth GJ, Stanford N, Majerus PW (1975) Acetylation of prostaglandin synthase by aspirin. Proc Natl Acad Sci 72(8): 3073-3076.

Rothwell PM, Price JF, Fowkes FGR, Zanchetti A, Roncaglioni MC, Tognoni G, Lee R, Belch JF, Wilson M, Mehta Z (2012) Short-term effects of daily aspirin on cancer incidence, mortality, and non-vascular death: analysis of the time course of risks and benefits in 51 randomised controlled trials. Lancet 379(9826): 1602-1612.

Rothwell PM, Wilson M, Elwin C-E, Norrving B, Algra A, Warlow CP, Meade TW (2010) Long-term effect of aspirin on colorectal cancer incidence and mortality: 20-year follow-up of five randomised trials. Lancet 376(9754): 1741-1750.

Ryder SP, Oyelere AK, Padilla JL, Klostermeier D, Millar DP, Strobel SA (2001) Investigation of adenosine base ionization in the hairpin ribozyme by nucleotide analog interference mapping. RNA 7(10): 1454-1463.

Sahasrabuddhe VV, Gunja MZ, Graubard BI, Trabert B, Schwartz LM, Park Y, Hollenbeck AR, Freedman ND, McGlynn KA (2012) Nonsteroidal anti-inflammatory drug use, chronic liver disease, and hepatocellular carcinoma. J Natl Cancer Inst 104(23): 1808-1814.

Sawaoka H, Tsuji S, Tsujii M, Gunawan ES, Sasaki Y, Kawano S, Hori M (1999) Cyclooxygenase inhibitors suppress angiogenesis and reduce tumor growth in vivo. Lab Invest 79(12): 1469-1477.

Sciulli M, Filabozzi P, Tacconelli S, Padovano R, Ricciotti E, Capone M, Grana M, Carnevale V, Patrignani P (2005) Platelet activation in patients with colorectal cancer. Prostaglandins Leukot Essent Fatty Acids 72(2): 79-83.

Shiff SJ, Koutsos MI, Qiao L, Rigas B (1996) Nonsteroidal antiinflammatory drugs inhibit the proliferation of colon adenocarcinoma cells: effects on cell cycle and apoptosis. Exp Cell Res 222(1): 179-188.

Shiff SJ, Shivaprasad P, Santini DL (2003) Cyclooxygenase inhibitors: drugs for cancer prevention. Curr Opin Pharmacol 3(4): 352-361.

Simon GM, Niphakis MJ, Cravatt BF (2013) Determining target engagement in living systems. Nat Chem Biol 9(4): 200-205.

Spitz GA, Furtado CM, Sola-Penna M, Zancan P (2009) Acetylsalicylic acid and salicylic acid decrease tumor cell viability and glucose metabolism modulating 6-phosphofructo-1-kinase structure and activity. Biochem Pharmacol 77(1): 46-53.
Stark LA, Reid K, Sansom OJ, Din FV, Guichard S, Mayer I, Jodrell DI, Clarke AR, Dunlop MG (2007) Aspirin activates the NF-kappaB signalling pathway and induces apoptosis in intestinal neoplasia in two in vivo models of human colorectal cancer. Carcinogenesis 28(5): 968-976.

Thun MJ, Jacobs EJ, Patrono C (2012) The role of aspirin in cancer prevention. Nat Rev Clin Oncol 9(5): 259-267.

Vane JR (1971) Inhibition of prostaglandin synthesis as a mechanism of action for aspirin-like drugs. Nat New Biol 231(25): 232-235.

Veitonmaki T, Tammela TL, Auvinen A, Murtola TJ (2013) Use of aspirin, but not other non-steroidal anti-inflammatory drugs is associated with decreased prostate cancer risk at the population level. Eur J Cancer 49(4): 938-945.

Velikyan I, Acharya S, Trifonova A, Foldesi A, Chattopadhyaya J (2001) The $\mathrm{pK}(\mathrm{a})$ 's of 2'-hydroxyl group in nucleosides and nucleotides. J Am Chem Soc 123(12): 2893-2894.

Wang C, Fu M, Mani S, Wadler S, Senderowicz AM, Pestell RG (2001) Histone acetylation and the cell-cycle in cancer. Front biosci 6: D610-D629.

Wang C, Weerapana E, Blewett MM, Cravatt BF (2014) A chemoproteomic platform to quantitatively map targets of lipid-derived electrophiles. Nat methods 11(1): 79-85.

Wang Q, Zhang Y, Yang C, Xiong H, Lin Y, Yao J, Li H, Xie L, Zhao W, Yao Y (2010) Acetylation of metabolic enzymes coordinates carbon source utilization and metabolic flux. Science 327(5968): 1004-1007.

Williams CS, Smalley W, DuBois RN (1997) Aspirin use and potential mechanisms for colorectal cancer prevention. J Clinical Invest 100(6): $1325-1329$.

Xu W, Li Y, Liu C, Zhao S (2013) Protein lysine acetylation guards metabolic homeostasis to fight against cancer. Oncogene 33(18): 2279-2285.

Xu X-M, Sansores-Garcia L, Chen X-M, Matijevic-Aleksic N, Du M, Wu KK (1999) Suppression of inducible cyclooxygenase 2 gene transcription by aspirin and sodium salicylate. Proc Natl Acad Sci 96(9): 5292-5297.

Yin M-J, Yamamoto Y, Gaynor RB (1998) The anti-inflammatory agents aspirin and salicylate inhibit the activity of ІкB kinase- $\beta$. Nature 396(6706): 77-80.

Zhao S, Xu W, Jiang W, Yu W, Lin Y, Zhang T, Yao J, Zhou L, Zeng Y, Li H (2010) Regulation of cellular metabolism by protein lysine acetylation. Science 327(5968): 1000-1004.

Zimmermann KC, Waterhouse NJ, Goldstein JC, Schuler M, Green DR (2000) Aspirin induces apoptosis through release of cytochrome $\mathrm{c}$ from mitochondria. Neoplasia 2(6): 505-513. 